\title{
THE EFFECT OF INTERMITTENT POSITIVE PRESSURE BREATHING ON THE LUNG COMPLIANCE AND INTRAPULMONARY MIXING OF GASES
}

\author{
BY \\ PETER A. EMERSON,* G. E. TORRES, AND HAROLD A. LYONS \\ From the Department of Medicine, State University of New York College of Medicine at New York City
}

(RECEIVED FOR PUBLICATION NOVEMBER 4, 1959)

Nims, Conner, and Comroe (1955) found that the compliance of the whole chest was smaller in anaesthetized than in conscious subjects; they suggested that this was probably due to the inability of the conscious subject to relax the muscles of inspiration. Howell and Peckett (1957) confirmed these findings, but pointed out that the compliance was being measured in different ways. In the conscious subject the inflating mechanism was the expanding action of the inspiratory muscles, whereas in positive pressure breathing the pattern of inflation of the lungs was no longer solely dependent on the changing shape of the thoracic cage. In these circumstances the two components of the thorax, the lungs and thoracic wall with the diaphragm, now represented a single visco-elastic resistance to the inflating pressure, and the pattern of inflation of the thorax depended on the magnitude and distribution of the combined resistances and might result in a different distribution of the inspired volume. They suggested that positive pressure breathing might result in over-distension of some areas of lung and under-ventilation of others. This would result in a lower effective volume of lung being inflated, and the compliance measured under such circumstances would be lower than that of the same lung when naturally and evenly inflated by the action of the respiratory muscles. In support of this theory they quoted their observations (Howell and Peckett, 1957) of values for lung compliance in 15 normal subjects using positive pressure methods. They drew attention to the larger values obtained with normal pressure methods in other patients by other workers, but when they measured the lung compliance in the same patients, first with normal pressure methods while conscious and later with positive pressure methods while paralysed and anaesthetized, the differences were much less than they expected $(154 \mathrm{ml}$. conscious, $109 \mathrm{ml}$. paralysed, per $\mathrm{cm}$. of water pressure).

\footnotetext{
*Present address: Westminster Hospital, London.
}

Thus the lower compliance of the whole chest found in anaesthetized as opposed to conscious subjects may be due to two factors: (1) Because the subjects are anaesthetized and paralysed. (2) Because, as suggested by Howell and Peckett, they are being inflated with intermittent positive pressure and that this results in an abnormal distribution of ventilation and therefore impaired compliance. To simplify the problem we have compared the compliance and the distribution of gases in the lungs during normal breathing and during intermittent positive pressure breathing in the same conscious and normal subjects.

\section{MethodS}

Advantage was taken of certain characteristics of the Bird pressure cycled intermittent positive pressure breathing apparatus to study the compliance of the lung and the mixing of gases in the lung in six normal subjects and to compare these results with those obtained during normal breathing. The subjects were trained to relax completely during intermittent positive pressure breathing and to allow the work of breathing to be done for them by the machine; this automatically cycles when a pre-set mouth pressure is reached. All the studies of compliance and mixing were made with the subjects in the sitting position as follows:

COMPLIANCE.-The intra-oesophageal pressure was taken as a close indication of the intrapleural pressure (Cherniack, Farhi, Armstrong, and Proctor, 1955; Howell and Peckett, 1957). It was recorded by the method of Fry, Stead, Ebert, Lubin, and Wells (1952) using an air-filled intra-oesophageal balloon $16 \mathrm{~cm}$. long, closed over the end of a $1.0 \mathrm{~mm}$. bore polythene tube which was connected to one side of a differential Statham gauge. The other side of the Statham gauge was connected to a side outlet of the mouthpiece of a Lilly type pneumotachygraph manometer head (Lilly, 1950). In this way the pressure difference across the lungs (mouth pressure minus intraoesophageal pressure) was obtained. Flow was measured by the pneumotachygraph and the volume was obtained by electronic integration. The electrical 


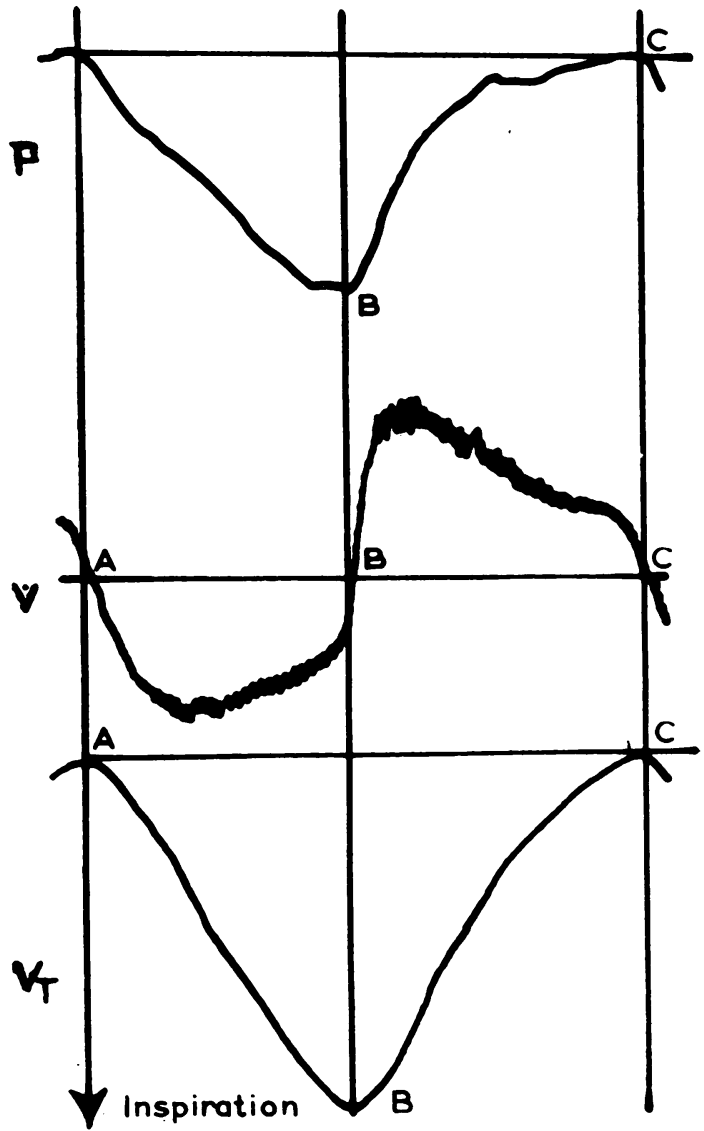

(a)

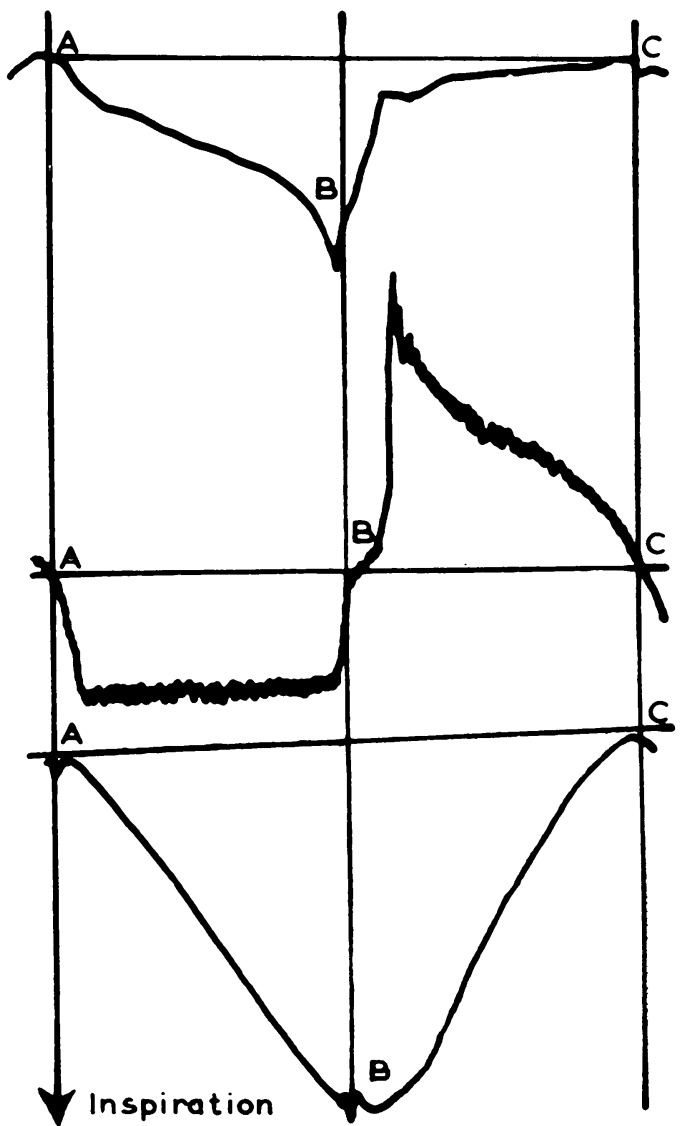

(b)

FIG. 1.-Records of pressure difference between mouth and oesophagus (P), flow (V), and tidal volume ( $\mathrm{V}_{\mathrm{T}}$ ). (a) During breathing at normal pressure; $(b)$ during intermittent positive pressure breathing.

signals were amplified and written on a four-channel photographic recorder. For the observations made with normal pressure breathing the mouthpiece was attached to one end of the prieumotachygraph manometer head; the other end was open to the atmosphere. For the positive pressure observations the other end of the pneumotachygraph manometer head was connected to the mouthpiece of the Bird intermittent positive pressure breathing apparatus. The form of the pressure, flow, and volume curves obtained in this way is shown for normal breathing in Fig. 1a, and for intermittent positive pressure breathing in Fig. 1b. The tracings during normal breathing are self-explanatory. Points $A$ and $C$ represent points of no flow at the end expiratory level. Points $B$ represent times of no flow at the maximum inspiratory volume. During intermittent positive pressure breathing the flow during inspiration is constant until the pressure set on the cycling valve is reached; then inspiratory flow ceases and after a pause passive expiration occurs. The distances between the lines $\mathrm{A}-\mathrm{C}$ to the points $B$ on the pressure and volume tracings for normal breathing and intermittent positive pressure breathing are a measure of the corresponding pressure and volume changes. Ten such measurements were made on each tracing and the means taken. These distances multiplied by the calibration factors gave the actual pressures and volumes concerned, and from these values the compliance of the lung, in litres per centimetre of water pressure, was calculated. Observations were made on each subject during normal breathing, voluntary hyperventilation, and during intermittent positive pressure breathing at pressures of 5,10 , and $15 \mathrm{~cm}$. of water respectively. These results appear in Table $I$.

Mixing.-The distribution of inspired gases during normal breathing, voluntary hyperventilation, and intermittent positive pressure breathing was studied in the same six normal subjects by an open circuit nitrogen washout method; this was also used to estimate the functional residual capacity (F.R.C.) in each instance. 
TABLE I

LUNG COMPLIANCE (LITRES CM. $\mathrm{H}_{2} \mathrm{O}$ PRESSURE) MEASURED DURING NORMAL BREATHING, VOLUNTARY HYPERVENTILATION, AND INTERMITTENT POSITIVE PRESSURE BREATHING

\begin{tabular}{|c|c|c|c|c|c|}
\hline \multirow{2}{*}{$\begin{array}{l}\text { Normal } \\
\text { Subject }\end{array}$} & \multirow{2}{*}{$\begin{array}{c}\text { Normal } \\
\text { Breathing }\end{array}$} & \multirow{2}{*}{$\begin{array}{l}\text { Voluntary } \\
\text { Hyperven- } \\
\text { tilation }\end{array}$} & \multicolumn{3}{|c|}{$\begin{array}{c}\text { Intermittent Positive Pressure } \\
\left.\text { Breathing (cm. } \mathrm{H}_{2} \mathrm{O}\right)\end{array}$} \\
\hline & & & $15 \mathrm{~cm}$ & $10 \mathrm{~cm}$. & $5 \mathrm{~cm}$ \\
\hline $\begin{array}{l}\text { P. E. } \\
\text { T. E. } \\
\text { T. R. } \\
\text { W. B. } \\
\text { T. G. } \\
\text { R. J. }\end{array}$ & $\begin{array}{l}0 \cdot 274 \\
0 \cdot 224 \\
0 \cdot 119 \\
0 \cdot 146 \\
0 \cdot 140 \\
0 \cdot 214\end{array}$ & $\begin{array}{l}0.302 \\
0.226 \\
0.081 \\
0.126 \\
0.142 \\
0.296\end{array}$ & $\begin{array}{l}0 \cdot 316 \\
0 \cdot 137 \\
0 \cdot 052 \\
0 \cdot 146 \\
0 \cdot 180 \\
0 \cdot 208\end{array}$ & $\begin{array}{l}0 \cdot 325 \\
0 \cdot 225 \\
0 \cdot 067 \\
0 \cdot 166 \\
0 \cdot 152 \\
0 \cdot 207\end{array}$ & $\begin{array}{l}0.333 \\
0.205 \\
0.078 \\
0.135 \\
0.154 \\
0.273\end{array}$ \\
\hline $\begin{array}{l}\text { Mean } \\
\text { values }\end{array}$ & $0 \cdot 186$ & $0 \cdot 195$ & & $0 \cdot 186$ & \\
\hline
\end{tabular}

The technique and apparatus used for the observations made during normal breathing and voluntary hyperventilation were similar to those described by Bouhuys, Hagstam, and Lundin (1956). By an arrangement of valves the subject inspired from a gas meter and Douglas bag previously washed out and filled with oxygen; expiration was into a Tissot spirometer as shown in Fig. 2. The air at the mouthpiece was continually sampled by a needle inserted as close to the mouth as possible and leading through a sampling tube to a nitrogen meter and vacuum pump. The concentration of nitrogen in the expired air could therefore be read on the nitrogen meter dial and continuously recorded by a Sanborne direct writer.

For the observations made during intermittent positive pressure breathing the expiratory valve of a Bird intermittent positive pressure breathing apparatus was connected by a very short length of brass tubing to the mouthpiece of the apparatus and valve $B$ was closed to disconnect the Douglas bag from the circuit. The patient inspired oxygen from the Bird intermittent positive pressure breathing apparatus, and the expired air was sampled by the needle at the mouthpiece and collected and mixed in the Tissot spirometer as in the experiments at normal pressures.

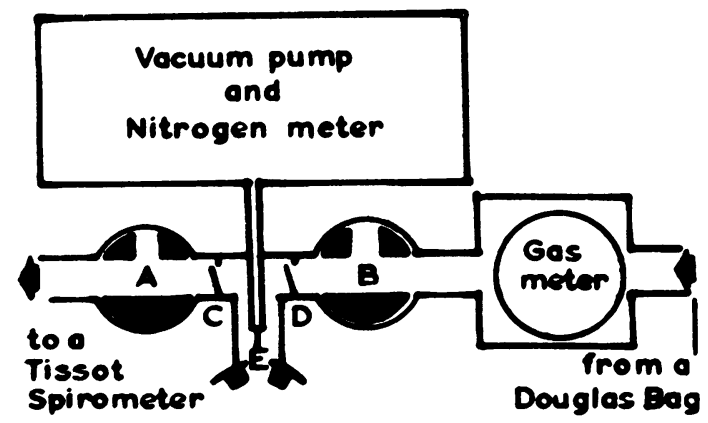

FIG. 2.-Diagram of the apparatus used for the collection of expired gas and for the measurement of the end tidal nitrogen concentrations. A and B are wide-bore two-way stopcocks; $C$ and $D$ are flaps of a unidirectional valve; $E$ is the sampling needle.
Procedure.-Before and between each experiment the whole apparatus was washed out with oxygen from the same cylinder, the unavoidable inert gas content of which was known and was in all cases below $0.9 \%$. The nitrogen meter was also calibrated before and between each experiment with oxygen mixtures of known nitrogen concentration. Each subject rested for at least 20 minutes before and between each study. At least two studies were made in each set of conditions to confirm that the results obtained for the F.R.C. checked to within $5 \%$.

Normal breathing was first studied in each subject ; normal breathing of atmospheric air was first established with valves $\mathbf{A}$ and $\mathbf{B}$ open to the atmosphere (Fig. 2). At the end of a normal expiration the valves were closed so that inspiration was from the oxygen-filled gas meter and Douglas bag and expiration was into the Tissot spirometer. After the start of oxygen breathing the end tidal nitrogen concentration fell progressively and these concentrations were recorded until the end tidal nitrogen concentration of the expired air had fallen to $2 \%$; valves $\mathbf{A}$ and $\mathbf{B}$ were then opened to the atmosphere at the end of a normal expiration. The volume and temperature of the expired gas in the Tissot spirometer were recorded.

Intermittent positive pressure breathing was next studied in the same patient by the arrangement with the Bird intermittent positive pressure breathing apparatus already described. From the volume of expired air collected in the Tissot spirometer and the number of breaths involved the tidal volume was calculated for the third part of each experiment. The rate was also noted.

Voluntary hyperventilation was studied last, using the same apparatus and circuit as for normal breathing. The dial of the gas meter was visible to the subject so that with practice and a metronome he was able to ventilate at a tidal volume and rate simila to the tidal volume and rate during the intermittent positive pressure breathing experiment.

The F.R.C.s and lung clearance indices were calculated, the nitrogen washout curves were graphically analysed, and the pulmonary nitrogen clearance delay percentages calculated as follows:

(a) The functional residual capacity was calculated for each experiment by the method described by Darling, Cournard, and Richards (1940) from the formula:

$$
\text { F.R.C.B.T.P.S. }=\left\{\frac{(V+D)\left(F_{s_{p}}-F_{T}\right)-C}{F_{a_{o}}-F_{a_{n}}}\right\}-X
$$

where $\mathrm{V}=$ volume of spirometer gas at blood temperature, ambient pressure and saturated with water vapour

$\mathrm{D}=$ known dead space of the spirometer circuit (560 ml.)

$\mathrm{F}_{\mathrm{Sp}}=$ percentage of nitrogen in the spirometer gas $\mathbf{F}_{\mathbf{T}}=$ percentage of nitrogen in the oxygen supply tank (below $0.9 \%$ ) 
$\mathrm{C}=$ correction for nitrogen excreted from the body during oxygen breathing $=$ (body surface area $\times 96.5$ ) $+35 \mathrm{ml}$. (Cournand, Yarmush, and Riley, 1941)

$\mathrm{Fa}_{\mathrm{o}}=$ percentage of nitrogen in the alveolar air before oxygen breathing $(81 \%)$

$\mathrm{Fan}_{\mathrm{n}}=$ percentage of nitrogen in the alveolar air at the end of oxygen breathing $(2.0 \%)$

$\mathrm{X}=$ dead space of the mouthpiece assembly between valve $A$ and the teeth $(106 \mathrm{ml}$. for intermittent positive pressure breathing, $52 \mathrm{ml}$. for normal pressure breathing)

(b) The lung clearance index was described by Becklake (1952) and is a measure of the overall efficiency of ventilation. It is the number of litres of oxygen required to wash out each litre of F.R.C. down to $2 \%$ end tidal nitrogen concentration. It is obtained by dividing the F.R.C. in litres into the total volume, in litres, of the expired gas collected in the spirometer. Becklake found the value in normals to be 10 litres or less.

(c) The pulmonary clearance delay percentage is an indication not of the overall efficiency of ventilation but of the uniformity of ventilation in the different parts of the lungs. It was described by Fowler, Cornish, and Kety (1952) based on the fundamental equation of Darling and others (1944) describing the fall of mean expired nitrogen concentration during oxygen breathing in an evenly ventilated space.

$F_{a_{n}}=F_{a_{o} w^{n}} \therefore \log F_{a_{n}}=\log F_{a_{o}}+n \log w_{\ldots} \ldots$ Equation 1 where $F_{a o}=$ alveolar nitrogen concentration before oxygen breathing

$\mathrm{Fan}_{\mathrm{n}}=$ alveolar nitrogen concentration after $\mathrm{n}$ breaths of oxygen

$\mathrm{w}=\frac{\mathrm{V}_{\mathbf{L}}}{\mathrm{V}_{\mathbf{L}}+\mathrm{V}_{\mathbf{T}}-\mathrm{V}_{\mathbf{D}}}$ and is called the alveolar dilution factor

where $\mathrm{V}_{\mathrm{L}}=$ functional residual capacity

$V_{T}=$ tidal volume

$V_{\mathbf{D}}=$ anatomical dead space

Fowler actually measured the mean expired nitrogen concentrations, but in the present experiments the end tidal nitrogen concentrations were measured as in the simplification described and justified by Bouhuys and others (1956). The end tidal nitrogen concentration (Fa) for each expiration was measured from the nitrogen washout tracing and plotted on a semilogarithmic scale against the number of breaths (n) as in Fig. 3. It will be seen from equation 1 that the nitrogen concentration falls exponentially during oxygen breathing and appears as a straight line on the semilogarithmic plot when the ventilation is uniform. The alveolar dilution factor, $w$, is represented by the slope of the straight line; any departure from this expresses uneven ventilation. This is found in many normal subjects, and the calculations given by Fowler and others (1952) indicate that in these circumstances the overall ventilation behaves as the sum of several lung spaces each ventilated in parallel at different rates represented by $w_{1}, w_{2}, \ldots$. etc. These values $\mathbf{w}_{1}, \mathbf{w}_{2}$, . . . etc., can be graphically determined by extrapolating the straight part of the curve towards zero and subtracting this line from the total curve. When the graph is resolved into two or more straight lines each represents a separate lung space itself evenly ventilated; the rate in each space is represented by an expression based on equation 1 (above). The values of $F a_{1} n, F a_{2} n, . .$. etc., and $F a_{10}$ and $F a_{2} O$, ... . etc., and $n$ are read off from the graph and the values of $w_{1}, w_{2}, \ldots$ etc., readily calculated.

The fractional volume of each space is found from:

$$
V_{L_{1}}=\frac{F_{a_{1} o}}{1-w_{1}}, V_{L_{2}}=\frac{F_{a_{2} o}}{1-w_{2}}, \ldots . . . \text { etc. }
$$

These formulae are derived from the mathematical expression for the sum of the terms of a decreasing geometric progression. $\quad \mathbf{V}_{L_{1}}, \quad \mathbf{V}_{\mathbf{L}_{2}}, \ldots$ etc., are theoretical numbers which represent the total amount of nitrogen washed out of each space; therefore, knowing the sum of all the fractions $V_{L_{1}}, V_{L_{2}}, \ldots$. etc., the fractional volume $f_{1}, f_{2}, \ldots$ etc., of each space can be calculated. That is,

$$
f_{1}=\frac{V_{L_{1}}}{V_{L_{1}}+V_{L_{2}}+V_{L_{3}}}, f_{2}=\frac{V_{L_{1}}}{V_{L_{1}}+V_{L_{2}}+V_{L_{3}}}, \ldots \text { etc. }
$$

Now Fowler and others (1952) showed that the average number of breaths during which an average nitrogen molecule remains in a space from which nitrogen is evenly and completely washed out is $\frac{1}{1-W}$. In a space with several fractions with different washout rates or uneven ventilation, the actual average number of breaths is $\frac{f_{1}}{1-w_{1}}+\frac{f_{2}}{1-w_{2}}, \ldots$ etc. It is also possible to calculate what the ideal number of breaths would be if the space had the same total $V_{L}$ and $\left(V_{T}-V_{D}\right)$ as the several fractions but was evenly ventilated, the alveolar dilution factor being $W$. In these circumstances this value of $W$ can be calculated because it can be shown that:

$$
\frac{1}{W}=\frac{f_{1}}{w_{1}}+\frac{f_{2}}{w_{2}}, \ldots . . \text { etc. }
$$

The ideal average number of breaths is then $\frac{1}{1-W}$.

By comparing the actual and ideal number of breaths an indication is obtained of the unevenness of ventilation. Even in normal subjects the actual number is usually larger than the ideal figure, and this difference is expressed in the pulmonary clearance delay percentage as follows:

Pulmonary clearance delay percentage $=$

$$
\left(\frac{\text { Actual average number of breaths }}{\text { Ideal average number of breaths }}-1\right) \times 100 \text {. }
$$

In normal subjects the percentage has been found to range from $0 \%$ to $100 \%$ (Bouhuys and others, 1952). 


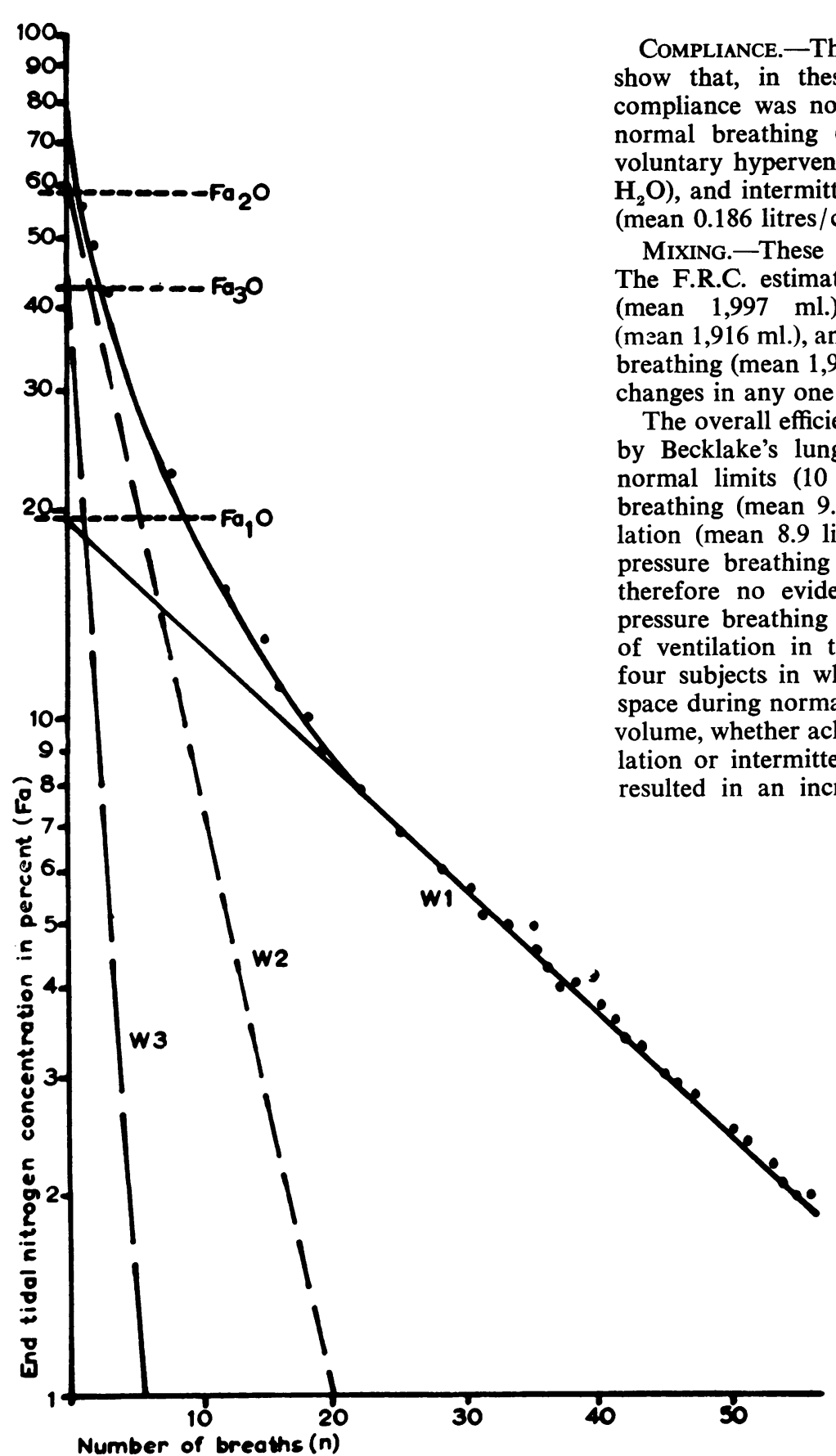

FIG. 3.-A nitrogen washout curve resolved into three straight lines; the lines represent hypcthetical lung spaces each of which is evenly ventilated at a different alveolar ventilation rate $w_{1}, w_{2}, w_{3}$.

\section{RESULTS}

results appearing in Table 1 Come nubjects, the lung compliance was not significantly different during 0.186 litres $/ \mathrm{cm} . \mathrm{H}_{2} \mathrm{O}$ ), 0.195 litres $/ \mathrm{cm}$. $\mathrm{H}_{2} \mathrm{O}$ ), and intermittent positive pressure breathing (mean 0.186 litres $/ \mathrm{cm} . \mathrm{H}_{2} \mathrm{O}$ ).

Mixing.-These results are shown in Table II. The F.R.C. estimations during normal breathing (mean 1,997 ml.), voluntary hyperventilation (mean $1,916 \mathrm{ml}$.), and intermittent positive pressure breathing (mean $1,940 \mathrm{ml}$.) did not show consistent Thes in any one direction.

iciency of ventilation as expressed clearance index was within breathing (mean 9.4 litres), voluntary hyperventilation (mean 8.9 litres), and intermittent positive pressure breathing (mean 9.6 litres). There was therefore no evidence that intermittent positive athing impaired the overall efficiency in these normal subjects. In the four subjects in whom there was more than one space during normal breathing an increase in tidal volume, whether achieved by voluntary hyperventilation or intermittent positive pressure breathing, resulted in an increase in the size of the more rapidly ventilated spaces at the expense of the poorly ventilated spaces. In the other two subjects there was only one space on normal breathing. In one (T. G.) both voluntary hyperventila- 3 . tion and intermittent positive $\delta$ pressure breathing simply $₹$ decreased the value of $\mathrm{W}$; 을 in the other (R. J.) the value of $\mathrm{W}$ was reduced on voluntary hyperventilation, but on

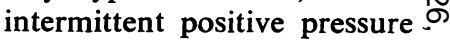
breathing an additional space $N$ appeared; in spite of this the $\underset{\omega}{\mathrm{N}}$ pulmonary clearance delay percentage remained un-o altered at zero, indicating that $\stackrel{\odot}{\Phi}$ the lungs were still evenly $\stackrel{\odot}{\rightarrow}$ ventilated. The ideal and $\underset{T}{0}$ actual number of breaths

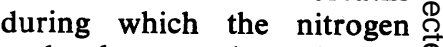
molecules remained in the $\stackrel{\mathbb{Q}}{\Omega}$ lungs during normal breathing $\bar{\sigma}$ 
TABLE II

\begin{tabular}{|c|c|c|c|c|c|c|c|c|c|c|c|c|c|c|}
\hline \multirow{3}{*}{$\begin{array}{c}\text { Nor- } \\
\text { mal } \\
\text { Sub- } \\
\text { ject } \\
\text { (Age } \\
\text { in Yr.) }\end{array}$} & \multirow{3}{*}{$\begin{array}{l}\text { Type } \\
\text { of } \\
\text { Breath- } \\
\text { ing* }\end{array}$} & \multirow{3}{*}{$\begin{array}{c}\text { Tidal } \\
\text { Volume } \\
\text { (l. } \\
\text { B.T.P.S.) }\end{array}$} & \multirow{3}{*}{$\begin{array}{c}\text { Res- } \\
\text { piratory } \\
\text { Rate } \\
\text { (per } \\
\text { min.) }\end{array}$} & \multirow{3}{*}{$\begin{array}{c}\text { Func- } \\
\text { tional } \\
\text { Residual } \\
\text { Capacity } \\
\text { (l. } \\
\text { B.T.P.S.) }\end{array}$} & \multirow{3}{*}{$\begin{array}{c}\text { Litres } \\
\text { to } \\
\text { Washout } \\
\text { Each } \\
\text { Litre of } \\
\text { F.R.C. }\end{array}$} & \multicolumn{6}{|c|}{ Ventilatory Systems } & \multirow{2}{*}{\multicolumn{2}{|c|}{$\begin{array}{c}\text { Average No. of } \\
\text { Breaths } \mathrm{N}_{2} \\
\text { Molecules } \\
\text { Remain in Lung }\end{array}$}} & \multirow{3}{*}{$\begin{array}{c}\text { Pul- } \\
\text { monary } \\
\text { Nitro- } \\
\text { gen } \\
\text { Delay } \\
(\%)\end{array}$} \\
\hline & & & & & & \multicolumn{2}{|c|}{ Slowest } & \multirow{2}{*}{$\mathbf{F}_{2}$} & \multirow{2}{*}{$\mathbf{w}_{2}$} & \multicolumn{2}{|c|}{ Fastest } & & & \\
\hline & & & & & & $\mathbf{F}_{1}$ & $\mathbf{W}_{\mathbf{1}}$ & & & $\mathbf{F}_{3}$ & $\mathbf{W}_{3}$ & Ideal & Actual & \\
\hline $\begin{array}{l}\text { P.E. } \\
\text { (35) }\end{array}$ & $\begin{array}{l}\text { N. } \\
\text { V.H. } \\
\text { I.P.P. }\end{array}$ & $\begin{array}{l}0 \cdot 65 \\
1 \cdot 50 \\
1 \cdot 20\end{array}$ & $\begin{array}{l}11 \\
10 \\
10\end{array}$ & $\begin{array}{l}2 \cdot 740 \\
2 \cdot 740 \\
2 \cdot 980\end{array}$ & $\begin{array}{r}10 \cdot 2 \\
8 \cdot 2 \\
10 \cdot 0\end{array}$ & $\begin{array}{l}0.50 \\
0 \cdot 24 \\
0.28\end{array}$ & $\begin{array}{l}0.944 \\
0.890 \\
0.933\end{array}$ & $\begin{array}{l}0.41 \\
0.47 \\
0.44\end{array}$ & $\begin{array}{l}0.854 \\
0.695 \\
0.739\end{array}$ & $\begin{array}{l}0.09 \\
0 \cdot 29 \\
0 \cdot 28\end{array}$ & $\begin{array}{l}0.636 \\
0.588 \\
0.659\end{array}$ & $\begin{array}{l}7 \cdot 6 \\
3 \cdot 3 \\
6 \cdot 1\end{array}$ & $\begin{array}{r}12 \cdot 0 \\
4 \cdot 5 \\
6 \cdot 7\end{array}$ & $\begin{array}{l}58 \\
36 \\
10\end{array}$ \\
\hline $\begin{array}{l}\text { T.E. } \\
\text { (35) }\end{array}$ & $\begin{array}{l}\text { N. } \\
\text { V.H. } \\
\text { I.P.P. }\end{array}$ & $\begin{array}{l}0.38 \\
1 \cdot 50 \\
1 \cdot 07\end{array}$ & $\begin{array}{l}16 \\
11 \\
16\end{array}$ & $\begin{array}{l}2 \cdot 260 \\
2 \cdot 100 \\
2 \cdot 000\end{array}$ & $\begin{array}{r}10.5 \\
10.0 \\
9.8\end{array}$ & $\overline{-}$ & 二 & $\frac{0.96}{0.67}$ & $\frac{0.945}{0.868}$ & $\begin{array}{l}0.03 \\
1.00 \\
0.33\end{array}$ & $\begin{array}{l}0.724 \\
0.691 \\
0.676\end{array}$ & $\begin{array}{r}15 \cdot 4 \\
3 \cdot 2 \\
4 \cdot 9\end{array}$ & $\begin{array}{r}18 \cdot 0 \\
3 \cdot 2 \\
6 \cdot 1\end{array}$ & $\begin{array}{r}17 \\
0 \\
25\end{array}$ \\
\hline$\underset{\text { (27) }}{\text { T.R. }}$ & $\begin{array}{l}\text { N. } \\
\text { V.H. } \\
\text { I.P.P. }\end{array}$ & $\begin{array}{l}0.32 \\
0.73 \\
0.65\end{array}$ & $\begin{array}{l}12 \\
20 \\
16\end{array}$ & $\begin{array}{l}1 \cdot 400 \\
1 \cdot 300 \\
1 \cdot 200\end{array}$ & $\begin{array}{r}9 \cdot 0 \\
8 \cdot 5 \\
10 \cdot 0\end{array}$ & $\overline{-}$ & - & $\frac{0.68}{0.42}$ & $\begin{array}{l}0.903 \\
0 . \overline{846}\end{array}$ & $\begin{array}{l}0.32 \\
1.00 \\
0.58\end{array}$ & $\begin{array}{l}0.750 \\
0.746 \\
0.639\end{array}$ & $\begin{array}{l}6 \cdot 6 \\
3.9 \\
3.9\end{array}$ & $\begin{array}{l}8 \cdot 3 \\
3 \cdot 9 \\
5 \cdot 0\end{array}$ & $\begin{array}{r}26 \\
0 \\
28\end{array}$ \\
\hline $\begin{array}{l}\text { W.B. } \\
(22)\end{array}$ & $\begin{array}{l}\text { N. } \\
\text { V.H. } \\
\text { I.P.P. }\end{array}$ & $\begin{array}{l}0.53 \\
1.57 \\
1.96\end{array}$ & $\begin{array}{r}11 \\
8 \\
13\end{array}$ & $\begin{array}{l}1.320 \\
1.450 \\
1 \cdot 210\end{array}$ & $\begin{array}{r}10.0 \\
8.0 \\
8.0\end{array}$ & $\begin{array}{l}0.24 \\
-\end{array}$ & $\begin{array}{c}0.946 \\
-\end{array}$ & $\begin{array}{c}0.39 \\
-\end{array}$ & $\begin{array}{c}0.728 \\
-\end{array}$ & $\begin{array}{l}0.37 \\
1.0 \\
1.0\end{array}$ & $\begin{array}{l}0.752 \\
0.637 \\
0.643\end{array}$ & $\begin{array}{l}4 \cdot 6 \\
2 \cdot 7 \\
2 \cdot 8\end{array}$ & $\begin{array}{l}7 \cdot 4 \\
2 \cdot 7 \\
2 \cdot 8\end{array}$ & $\begin{array}{r}63 \\
0 \\
0\end{array}$ \\
\hline $\begin{array}{l}\text { T.G. } \\
\text { (27) }\end{array}$ & $\begin{array}{l}\text { N. } \\
\text { V.H. } \\
\text { I.P.P. }\end{array}$ & $\begin{array}{l}0.69 \\
1.72 \\
1.33\end{array}$ & $\begin{array}{r}20 \\
6 \\
9\end{array}$ & $\begin{array}{l}1 \cdot 130 \\
1.000 \\
1 \cdot 110\end{array}$ & $\begin{array}{r}9.0 \\
11.4 \\
10.7\end{array}$ & 二 & $\overline{-}$ & E & 二 & $\begin{array}{l}1.0 \\
1.0 \\
1.0\end{array}$ & $\begin{array}{l}0.792 \\
0.429 \\
0.653\end{array}$ & $\begin{array}{l}5 \cdot 0 \\
1 \cdot 8 \\
2 \cdot 8\end{array}$ & $\begin{array}{l}5 \cdot 0 \\
1 \cdot 8 \\
2 \cdot 8\end{array}$ & $\begin{array}{l}\mathbf{0} \\
\mathbf{0} \\
\mathbf{0}\end{array}$ \\
\hline $\begin{array}{l}\text { R.J. } \\
\text { (30) }\end{array}$ & $\begin{array}{l}\text { N. } \\
\text { V.H. } \\
\text { I.P.P. }\end{array}$ & $\begin{array}{l}0.98 \\
1.44 \\
1.50\end{array}$ & $\begin{array}{l}5 \\
7 \\
6\end{array}$ & $\begin{array}{l}3 \cdot 130 \\
3 \cdot 010 \\
3 \cdot 140\end{array}$ & $\begin{array}{l}7 \cdot 5 \\
7 \cdot 4 \\
9 \cdot 0\end{array}$ & E & 二 & $\overline{0.69}$ & $\overline{0.667}$ & $\begin{array}{l}1 \cdot 0 \\
1.0 \\
0.31\end{array}$ & $\begin{array}{l}0.822 \\
0.791 \\
0.428\end{array}$ & $\begin{array}{l}5 \cdot 6 \\
4 \cdot 8 \\
2 \cdot 3\end{array}$ & $\begin{array}{l}5 \cdot 6 \\
4 \cdot 8 \\
2 \cdot 3\end{array}$ & $\begin{array}{l}\mathbf{0} \\
\mathbf{0} \\
\mathbf{0}\end{array}$ \\
\hline $\begin{array}{c}\text { Mean } \\
\text { values }\end{array}$ & $\begin{array}{l}\text { N. } \\
\text { V.H. } \\
\text { I.P.P. }\end{array}$ & $\begin{array}{l}0.59 \\
1.41 \\
1.28\end{array}$ & $\begin{array}{l}12 \\
10 \\
12\end{array}$ & $\begin{array}{l}1.997 \\
1.916 \\
1.940\end{array}$ & $\begin{array}{l}9 \cdot 4 \\
8 \cdot 9 \\
9 \cdot 6\end{array}$ & & & & & & & $\begin{array}{l}7 \cdot 5 \\
3 \cdot 3 \\
3 \cdot 8\end{array}$ & $\begin{array}{l}9 \cdot 4 \\
3 \cdot 5 \\
4 \cdot 3\end{array}$ & $\begin{array}{r}27.0 \\
6.0 \\
10 \cdot 5\end{array}$ \\
\hline
\end{tabular}

* $\mathbf{N}=$ normal; V.H. = voluntary hyperventilation; I.P.P. = intermittent positive pressure.

decreased during voluntary hyperventilation and intermittent positive pressure breathing; the change was reflected by the decrease in the clearance delay from a mean of $27.0 \%$ to $6.0 \%$ and $10.5 \%$ respectively. These changes represent a tendency towards increased uniformity of mixing and are a function of the increased tidal volume produced by voluntary hyperventilation or intermittent positive pressure breathing; they make it clear that intermittent positive pressure breathing did not have any detrimental effect on the uniformity of ventilation in these normal subjects.

\section{Discussion}

The published reports about the effect of intermittent positive pressure breathing on the compliance of the thorax are confusing because different authors have measured the whole chest or lung compliance under different conditions so that comparisons are often impossible. Nims and others (1955) found that the values for the whole chest compliance obtained in six conscious subjects by the relaxation pressure technique of Rahn, Otis, Chadwick, and Fenn (1946) were less than these obtained in the same subjects when they were anaesthetized and inflated by a positive pressure method. Howell and Peckett (1957) also found that both the whole chest and lung compliances in anaesthetized and paralysed subjects, inflated by a positive pressure method, were less than they expected from the results obtained by other workers under normal pressure conditions. In the paretic patients studied by Opie, Spalding, and Stott (1959) the average lung compliance during intermittent positive pressure breathing was less than half that during spontaneous breathing.

However, when Howell and Peckett (1957) measured the lung compliance in the same normal subjects, first when conscious and breathing spontaneously and later when anaesthetized and inflated by a positive pressure method, the differences were much smaller than they had expected. Similarly there were no significant differences in the lung compliances measured by Opie and others (1959) in four normal conscious subjects, first during normal breathing and later when relaxing in a tank respirator. The mechanical forces acting on the chest wall and lungs of a voluntary relaxed subject are the same whether the pressure difference across the thorax is produced by the negative extrathoracic pressure of a tank respirator or by the positive intrathoracic pressure of an intermittent positive pressure machine. The present results, which showed no significant difference in the compliance of the lungs of conscious normal subjects whether measured during normal pressure or intermittent positive pressure breathing, agree with the findings of Opie and others (1959) in their normal subjects. 
The evidence of the present study that there was no significant decrease in the overall efficiency of ventilation, nor in the uniformity of ventilation during intermittent positive pressure breathing compared with normal breathing, is in keeping with the absence of any significant change in the lung compliance in these same circumstances.

It seems unlikely then that impairment of the even distribution of ventilation during intermittent positive pressure breathing is the cause of the observed decrease in the total thoracic compliance reported by Nims and others (19.55) in anaesthetized patients whose lungs were inflated by intermittent positive pressures.

The present observations refer only to lungs in which the ventilation is relatively even. There is some theoretical and experimental evidence that where ventilation is initially uneven such an increase in the flow rate, as might be produced by intermittent positive pressure breathing, will increase the unevenness of ventilation and decrease the compliance (Otis, McKerrow, Bartlett, Mead, McIlroy, Selverstone, and Radford, 1956). Such may be the explanation of the decreased lung compliance in paretic patients during intermittent positive pressure breathing reported by Opie and others (1959).

However, we were unable to show any decreased overall efficiency of ventilation or increased unevenness of ventilation in emphysematous patients during intermittent positive pressure, as opposed to normal breathing (Torres, Emerson, and Lyons, 1960). The flow rates used for these intermittent positive pressure experiments were relatively low $\left(1=1 \frac{1}{2}\right.$ litres $/ \mathrm{sec}$.) and it is possible that with higher flow rates some increased unevenness of ventilation may occur. It appears that the decreased compliance of the whole thorax found by Nims and others (1955) in anaesthetized subjects must be related to the anaesthetized state and not to the method of intermittent positive pressure breathing. One possible explanation of the observed facts is that the conscious subject is unable voluntarily to suspend his breathing and that the normal inspiratory tone is responsible for the greater compliance in conscious subjects (Gordon, Fainer, and Ivy, 1950). Van Liew (1954) showed that in dogs vagal blockade increased the whole chest compliance, so it is possible that anaesthetic agents, such as cyclopropane, which sensitize the vagal stretch reflexes (Whitteridge and Bülbring, 1944), may actually decrease the whole chest compliance by increasing expiratory muscle tone.

The other possible explanation is that anaesthesia decreases the total chest compliance by decreasing the compliance of the lung in some $\frac{\overrightarrow{\bar{P}}}{\frac{\vec{\rho}}{9}}$ way. Butler and Smith (1957) did find that in? anaesthetized patients the compliance of the chest $\frac{\bar{\sigma}}{\bar{c}}$ wall was not below the expected value but that $\frac{\pi}{\widetilde{\sigma}}$ the compliance of the lung was reduced. They suggested that the reduced lung compliance during कै anaesthesia was due to areas of alveolar collapse $\vec{\circ}$ decreasing the effective lung volume. Similarly $\overrightarrow{-}$ Bromage (1958) found that in anaesthetized subjects $\vec{\omega}$ the total thoracic compliance was decreased by noxious stimuli such as ether inhalation; as this $\vec{x}$ decrease was only a little reduced by neuro- $\vec{r}$ muscular paralysis, he concluded that the mainis effect must have been on the compliance of the $\vec{N}$ lung and not the chest wall. He suggested that + the mechanism was some degree of broncho-음 constriction induced by the ether and preventing the inflation of areas of peripheral alveolar $\subseteq$ collapse and thereby decreasing the effective lung $\Phi$ volume and compliance.

What is now needed to confirm or deny these speculations is a study comparing the lung and chest wall compliance, measured by the sameo intermittent positive pressure method in the same subjects before and after the induction of anaesthesia.

\section{SUMMARY}

Previous authors have advanced several explana- $\overrightarrow{\overrightarrow{0}}$ tions for the decreased values obtained with 3 positive pressure inflation for the total thoracic compliance during anaesthesia. One theory is that intermittent positive pressure inflation impairs the even distribution of gases in the lungs and therefore decreases the actual lung compliance.

The compliance of the lungs and the mixing of $\frac{3}{3}$ gases in the lungs have been studied in six. conscious normal subjects during intermittent $\frac{\beta}{3}$ positive pressure breathing, voluntary hyperventilation, and normal breathing. The overallo efficiency of ventilation was measured by Beck- $\rightarrow$ lake's lung clearance index and the evenness of ventilation by Fowler's pulmonary nitrogen delay percentage. The evidence was that the lung compliance was not decreased by intermittent positive pressure inflation in normal conscious subjects; $\omega$ neither was there any decrease in the overallo efficiency of ventilation nor impairment of theo evenness of ventilation during intermittent positive $\Phi$ pressure breathing compared with normal ${ }^{\circ}$ breathing.

It is concluded that the decreased compliance

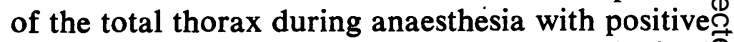
pressure inflation is related to the anaesthetized $\stackrel{\mathbb{Q}}{\varrho}$ state and is not due to the method of intermittento positive pressure breathing. Possible mechanisms are discussed. 


\section{REFERENCES}

Becklake, M. R. (1952). Thorax, T, 111

Bouhuys, A., Hagstam, K. E., and Lundin, G. (1956). Acta physiol. scand., 35, 289.

Bromage, P. R. (1958). Clin. Sci., 17, 217.

Butler, J., and Smith, B. H. (1957). Ibid., 16, 125.

Cherniack, R. M., Farhi, L. E., Armstrong, B. W., and Proctor, D. F. (1955). J. appl. Physiol., 8, 203.

Cournand, A., Yarmush, I. G., and Riley, R. L. (1941). Proc. Soc. exp. Biol.'(N.Y.), 48, 280.

Darling, R. C., Cournand, A., and Richards, D. W. (1940). J. clin. Invest., 19, 609.

- - (1944). Ibid., 23, 55.

Fowler, W. S., Cornish, E. R., and Kety, S. S. (1952). Ibid., 31, 40.

Fry, D. L., Stead, W. W., Ebert, R. V., Lubin, R. I., and Wells, H. S. (1952). J. Lab. clin. Med., 40, 664.

Gordon, A. S., Fainer, D. C., and Ivy, A. C. (1950). J. Amer. med. Ass., 144, 1455.
Howell, J. B. L., and Peckett, B. W. (1957). J. Physiol. (Lond.), 136,1

Lilly, J. C. (1950). Methods in Medical Research, Vol. 2, p. 113. The Year Book Publishers, Chicago.

Nims, R. G., Conner, E. H., and Comroe, J. H. (1955). J. clin. Invest., 34, 744.

Opie, L. H., Spalding, J. M. K., and Stott, F. D. (1959). Lancet, 1, 545.

Otis, A. B., McKerrow, C. B., Bartlett, R. A., Mead, J., Mcllroy, M. B., Selverstone, N. J., and Radford, E. P. (1956). J. appl. Physiol., 8, 427.

Rahn, H., Otis, A. B., Chadwick, L. E., and Fenn, W. O. (1946). Amer. J. Physiol., 146, 161.

Torres, G. E., Emerson, P. A., and Lyons, H. A. (1960). J. Amer. $m \epsilon d$. Ass. To be published.

Van Liew, H. D. (1954). Amer. J. Physiol., 177, 161.

Whitteridge, D., and Bülbring, E. (1944). J. Pharmacol., 81, 340. 